\title{
Autocrine down-regulation of glucocorticoid receptors by interleukin-11 in human osteoblast-like cell lines
}

\author{
A Dovio, M L Sartori, R G Masera, B Ceoloni, G Reimondo, \\ P Prolo ${ }^{1}$, S Racca ${ }^{2}$ and A Angeli
}

Clinica Medica Generale, Dipartimento di Scienze Cliniche e Biologiche, University of Turin, Regione Gonzole 10, 10043 Orbassano (TO), Italy

${ }^{1}$ Division of Oral Biology and Medicine, UCLA School of Dentistry and Dental Research Institute, 10833 Le Conte Avenue, Box 951688, Los Angeles, California 90095-1668, USA

${ }^{2}$ Farmacologia, Dipartimento di Scienze Cliniche e Biologiche, University of Turin, Regione Gonzole 10, 10043 Orbassano (TO), Italy

(Requests for offprints should be addressed to A Angeli; Email: alberto.angeli@unito.it)

\begin{abstract}
It has recently been suggested that interleukin (IL)-11 plays a role in the pathogenesis of glucocorticoid (GC)induced osteoporosis. IL-11 belongs to the gp130 cytokine family, which includes also IL-6. We have previously investigated GC-IL-6 interplay, showing that GC inhibits IL-6 release and IL-6 up-regulates GC receptor (GR) numbers in the human osteoblast-like cell lines Saos-2 and MG-63, which constitutively have an opposite pattern of expression for GR, IL-11, IL-6, alkaline phosphatase and osteoprotegerin (OPG). The aim of this study was to investigate GC-IL-11 interplay in the same two cell lines. First, cells were incubated with cortisol $(0 \cdot 01-1 \mu \mathrm{M})$ for $20 \mathrm{~h}$ in the presence and in the absence of a known IL-11 secretagogue (IL-1 $\beta)$; cell media were assayed for IL-11 by ELISA. Secondly, cells were incubated with IL-11 (0-1$100 \mathrm{ng} / \mathrm{ml}$ ) or specific anti-IL-11 monoclonal antibody for $20 \mathrm{~h}$, and then assayed for GR by a radioligand binding assay. Similar to IL-6, both constitutive and IL-1 $\beta$ inducible IL-11 release were dose-dependently inhibited
\end{abstract}

by cortisol $(P<0 \cdot 01)$; at variance with IL-6, exogenous IL-11 dose-dependently decreased GR numbers in MG-63 cells $(P<0 \cdot 05)$, while anti-IL-11 antibody significantly increased GR numbers in both cell lines $(P<0 \cdot 05)$. IL-11-induced reduction of GR in MG-63 cells was confirmed by Western blot analysis. While exerting opposite effects on GR numbers, neither IL-6 nor IL-11 significantly modified GC-dependent inhibition of OPG release. Our data indicate that even physiological concentrations of cortisol negatively modulate IL-11 secretion and demonstrate, for the first time, an inhibitory effect of the cytokine on GR. Thus, the concept of autocrine-paracrine loops that modulate GC action and involve gp130 cytokines is corroborated. These loops could have clinical relevance for the dynamics of bone loss in patients given GC and having high concentrations of these cytokines in the bone microenvironment.

Journal of Endocrinology (2003) 177, 109-117

\section{Introduction}

Interleukin (IL)-11 belongs to the gp130 cytokine family, which also contains IL-6, oncostatin $M$, leukemia inhibitory factor, ciliary neurotrophic factor, cardiotrophin 1 (the recently discovered novel neurotrophin-1/cardiotrophinlike cytokine) and Kaposi's sarcoma-associated herpesvirus IL-6 (Nicholas et al. 1997, Heinrich et al. 1998, Senaldi et al. 1999). The activities of these cytokines are mediated through formation of receptor complexes sharing the signal-transducing glycoprotein gp130; such receptor complexes activate tyrosine kinases of the Janus family and the tyrosine phosphatase SHP-2, which in turn transduce via the STAT family of transcription factors and the MAP kinases pathway respectively (Heinrich et al. 1998).
Glucocorticoid (GC)-induced osteoporosis is the most frequent secondary osteoporosis. Its prominent pathogenetic feature is decreased bone formation; as far as bone resorption is concerned, an early and transient increase is followed by sustained decrease (Canalis \& Giustina 2001, Weinstein 2001). IL-11 has been consistently shown to up-regulate osteoclastogenesis (Girasole et al. 1994), mainly through up-regulation of expression of receptor activator of nuclear factor-kappaB (NF- $\kappa \mathrm{B}$ ) ligand (RANKL) by cells of the osteoblastic lineage (Ragab et al. 2002). In vitro, IL-11 stimulates osteoblast differentiation of mouse mesenchymal progenitors (Taguchi et al. 1998, Suga et al. 2001). In vivo, IL-11 administration is able to recover impaired osteoblastogenesis and osteoclastogenesis seen in the P6 strain of senescence-accelerated mice 
Table 1 Functional phenotype of MG-63 and Saos-2 cells. Data are expressed as means \pm S.E. (number of independent experiments)

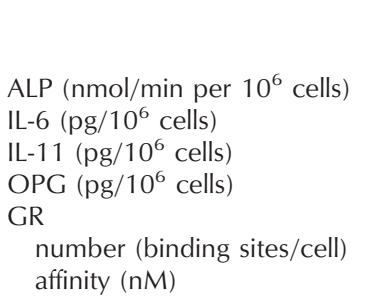

ALP, alkaline phosphatase activity.

\begin{tabular}{|c|c|}
\hline MG-63 & Saos-2 \\
\hline$<1(n=3)$ & $1058 \pm 170(n=6)$ \\
\hline $1874 \pm 729(n=10)$ & $4 \cdot 6 \pm 1 \cdot 2(n=3)$ \\
\hline $43 \pm 20(n=6)$ & $572 \pm 35(n=6)$ \\
\hline $39273 \pm 10912(n=8)$ & $824 \pm 98(n=4)$ \\
\hline $110380 \pm 4499(n=11)$ & $31783 \pm 1847(n=12)$ \\
\hline $2 \cdot 8 \pm 0 \cdot 3(n=11)$ & $3 \cdot 5 \pm 0 \cdot 4(n=12)$ \\
\hline
\end{tabular}

(Kodama et al. 1998). Transgenic mice overexpressing IL-11 show increased cortical thickness and are protected from age-related cortical bone loss, without any apparent alteration of osteoclastogenesis and bone resorption (Takeuchi et al. 2002). Most importantly, IL-11 has been shown to prevent, at least partially, dexamethasone (Dex)induced apoptosis of osteoblasts (Kido et al. 2002). Taken together with the well-known inhibitory effect of GC upon IL-11 synthesis (Kim et al. 1999), these data have been interpreted as compatible with a role for IL-11 as a mediator of GC effects on bone.

We have recently investigated GC-IL-6 interplay in human osteoblast-like cells: we have confirmed that physiological concentrations of the naturally occurring GC cortisol dose-dependently decrease IL-6 secretion (Dovio et al. 2001a), and demonstrated for the first time that IL-6 modulates GC receptor (GR) numbers in both an autocrine and a paracrine way (Dovio et al. 2001b). GR number is a key determinant of GC sensitivity both in vitro and in vivo (Reichardt et al. 2000, Laudet \& Gronemeyer 2002). Indeed, while the effects of GC on gp130mediated cytokines secretion and activity have been widely investigated, little attention has been paid to these cytokines as potential modulators of the tissue sensitivity to GC. In the present study, we have investigated GC-IL-11 interplay in the two widely used and well-characterized human osteosarcoma cell lines, Saos-2 and MG-63, which constitutively have a divergent pattern of expression for IL-6, IL-11, alkaline phosphatase and GR. We report that, in contrast to IL-6, IL-11 exerts an autocrine-paracrine down-regulation of GR in Saos-2 and MG-63 cells. We also found that neither IL-6-induced nor IL-11-induced changes of GR number were paralleled by significant increase and decrease respectively, of a typical GRmediated effect, i.e. inhibition of osteoprotegerin (OPG) release.

\section{Materials and Methods}

\section{Materials}

Recombinant human (h) IL-11, hIL-6 and anti-hIL-11 and anti-hIL-6 monoclonal antibodies (mouse $\mathrm{IgG}_{2 \mathrm{~B}}$, clone \#22616 and mouse $\operatorname{IgG}_{1}$, clone \#6708 respectively) were purchased from R\&D Systems (Abingdon, Oxon, UK); they were reconstituted using sterile PBS containing $1 \% \mathrm{BSA}$, stored at $-20^{\circ} \mathrm{C}$, and diluted to the appropriate concentrations immediately before experiments.

Dex and cortisol (Sigma-Aldrich, Milan, Italy) were initially dissolved in 95\% ethanol and then diluted in PBS to give a $1 \mathrm{mM}$ stock solution, which was stored at $-20{ }^{\circ} \mathrm{C}$. The steroids were promptly diluted to final concentrations before each experiment and binding assay.

$\left[1,2,4,6,7-{ }^{3} \mathrm{H}\right]$ Dex was purchased from Amersham International (Amersham, Bucks, UK); before each binding assay, solvent was removed under a nitrogen stream and labeled steroid was then dissolved to final concentrations in appropriate medium. Scintillation fluid and scintillation vials were purchased from Packard Instruments Company (Meriden, CT, USA).

Bradford protein assay kit and horseradish peroxidaselabeled protein A were purchased from Biorad Laboratories (Hercules, CA, USA); all other reagents for Western blotting were purchased from Sigma-Aldrich.

\section{Cells and culture conditions}

The human osteosarcoma cell lines Saos-2 and MG-63 are two widely used experimental models for investigating osteoblast function. Saos-2 cells were kindly provided by Prof. M L Brandi, University of Florence; MG-63 cells were purchased from Interlab Cell Line Collection (National Institute for Cancer Research, Genoa, Italy). Saos-2 cells constitutively express alkaline phosphatase activity, as measured by a colorimetric method, while MG-63 cells do not (Table 1; results are expressed as nmol p-nitrophenol/min per $10^{6}$ cells). Saos- 2 and MG-63 cell lines were cultured in McCoy medium (Sigma-Aldrich) and DMEM (Euroclone, Wetherby, UK) respectively, enriched with $10 \%(\mathrm{v} / \mathrm{v})$ heat-inactivated fetal bovine serum (FBS), $2 \mathrm{mM}$ L-glutamine, $100 \mathrm{IU} / \mathrm{ml}$ penicillin and $100 \mu \mathrm{g} / \mathrm{ml}$ streptomycin (Sigma-Aldrich), in a humidified atmosphere of $95 \%$ air $/ 5 \% \mathrm{CO}_{2}$ at $37^{\circ} \mathrm{C}$.

For experiments, cells were plated into six-well plates and treated when subconfluent. First, constitutive and 
IL-1 $\beta$-inducible IL-11 release and modulatory effects of cortisol were evaluated: both cell lines were treated with IL-1 $\beta(10 \mathrm{ng} / \mathrm{ml})$, in the presence or absence of cortisol $(0 \cdot 01-1 \mu \mathrm{M})$, for $20 \mathrm{~h}$. Cells were also incubated with IL-6 $(0 \cdot 1-2 \mathrm{ng} / \mathrm{ml})$ or with an anti-hIL-6 antibody $(100 \mathrm{ng} / \mathrm{ml})$ for $20 \mathrm{~h}$. After treatment, cell culture media were harvested and assayed for IL-11.

To test the effects of IL-11 on GR concentration and affinity, both cell lines were treated with increasing concentrations of IL-11 $(0 \cdot 1-100 \mathrm{ng} / \mathrm{ml})$ or anti-IL-11 antibody (Saos-2: $1 \mu \mathrm{g} / \mathrm{ml}$; MG-63: 0.5 $\mu \mathrm{g} / \mathrm{ml}$ ) for $20 \mathrm{~h}$; in the absence of previous data on IL-11 action on GR, this incubation time was chosen according to the results of previous studies investigating the effects of IL-6 on GR (Rakasz et al. 1993, Dovio et al. 2001b). After treatment, cell culture media and cells were assayed for IL-6 and GR respectively.

Finally, to study the effects of cytokines on GC sensitivity, both cell lines were incubated with vehicle, IL-6 (2 ng/ml) or IL-11 (100 ng/ml) for $20 \mathrm{~h}$; then cell culture supernatants were harvested and the same cells were further incubated for $20 \mathrm{~h}$ with either vehicle, or cortisol and Dex (0.01-1 $\mu \mathrm{M})$. After treatment, cell culture media were assayed for OPG.

\section{Cell count and viability}

Cells were counted and evaluated for viability by trypan blue stain. Briefly, $50 \mu$ l of cell suspension were incubated in a dark tube with $50 \mu \mathrm{l}$ of $0 \cdot 4 \%(\mathrm{w} / \mathrm{v})$ trypan blue solution, mixed thoroughly and allowed to stand for $5 \mathrm{~min}$. Thereafter, the trypan blue-cell suspension mixture was transferred to both chambers of a hemocytometer, and cell viability was calculated as the ratio between total viable cells (unstained) and total cells (stained+unstained).

\section{IL-6, IL-11, OPG and soluble RANKL (sRANKL) ELISA}

After treatment, cell culture media were collected, centrifuged for $10 \mathrm{~min}$ at $2500 \mathrm{~g}$ at $4{ }^{\circ} \mathrm{C}$, and the supernatants frozen at $-20^{\circ} \mathrm{C}$. Supernatants were diluted when necessary before assay. IL-6, IL-11, OPG and sRANKL were measured in duplicate by sensitive ELISAs using commercially available kits (IL-6 and IL-11: R\&D Systems; OPG and sRANKL: Immundiagnostik, Bensheim, Germany). Detection limits were less than $0 \cdot 7,8,2.7$ and $80 \mathrm{pg} / \mathrm{ml}$ respectively; intra- and inter-assay coefficient of variation $(\mathrm{CV})$ values were $<10 \%$ - samples with CV values $>10 \%$ were re-assayed. According to the manufacturer's information, OPG ELISA detects all forms of OPG (i.e. monoand dimeric forms, free and complexed with sRANKL). sRANKL ELISA exploits recombinant OPG-precoated wells, and thus detects free sRANKL only (i.e. not OPG-complexed sRANKL). Results are expressed as $\mathrm{pg} / 10^{6}$ cells.

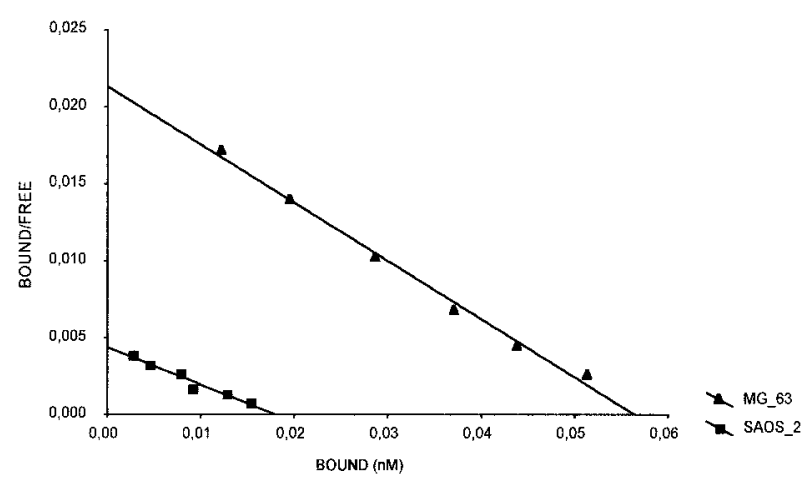

Figure 1 Representative Scatchard plot: the slope gives the negative reciprocal of the binding affinity, the intercept on the $x$-axis the number of receptors. MG-63, $R=0.997$; Saos-2, $R=0.976$.

\section{GC binding assay}

After treatment, cells were washed twice with PBS and incubated with fresh phenol red-free medium containing 10\% charcoal-stripped FBS for $1 \mathrm{~h}$; subsequently, medium was removed and cells were incubated for $1 \mathrm{~h}$ with binding solutions containing high specific activity (82 $\mathrm{Ci} / \mathrm{mM})\left[1,2,4,6,7-{ }^{3} \mathrm{H}\right]$ Dex at six progressively decreasing concentrations $(46-2 \cdot 25 \mathrm{nM})$, in the presence or absence of 200-fold molar excess of unlabeled Dex, to determine non-specific and total binding respectively. After incubation, cells were washed five times with ice-cold PBS buffer, scraped into $1 \mathrm{M} \mathrm{NaOH}$ and transferred to scintillation vials with scintillation fluid. Activity was counted by a scintillation $\beta$-counter. Six tubes with labeled Dex alone were assessed for total activity. Specific binding was calculated, at each GC concentration, as the difference between the totally bound reactivity and the nonspecifically bound reactivity. Non-specific binding was calculated from the aliquots containing the 200-fold molar excess of non-radioactive Dex, assuming that non-specific binding was non-saturable and linearly related to the concentration of free GC. GR concentration and equilibrium dissociation constant $\left(K_{\mathrm{d}}\right)$ were determined by the Scatchard method (Fig. 1).

\section{Western blot analysis}

MG-63 cells were harvested and resuspended in lysis buffer $(0 \cdot 1 \mathrm{M}$ Tris-HCl, pH $6 \cdot 8,2.5 \%$ SDS, $0.02 \mathrm{mM}$ phenylmethylsulfonyl fluoride). Cell lysates were then sonicated and immediately frozen at $-20{ }^{\circ} \mathrm{C}$. A sample was taken for protein estimation by the Bradford protein assay.

One hundred micrograms of protein were resolved by electrophoresis through $8 \%$ SDS-polyacrylamide gels and electrophoretically transferred to nitrocellulose in Tris-glycine buffer ( $25 \mathrm{mM}$ Tris-HCl, $\mathrm{pH} 8 \cdot 3,250 \mathrm{mM}$ glycine, $0.05 \%$ SDS, $20 \%$ methanol). Membranes were 
stained with Ponceau S $(0 \cdot 2 \%$ in $5 \%$ trichloroacetic acid) to evaluate loading equivalency and transfer efficiency, and blocked with PBS containing 0.5\% non-fat milk and $0 \cdot 1 \%$ Tween 20 . The blot was then washed with PBS and incubated overnight at $4{ }^{\circ} \mathrm{C}$ with an anti-GR $\alpha$ polyclonal antibody (rabbit polyclonal IgG, P-20; Santa Cruz Biotechnology, Santa Cruz, CA, USA). Subsequently, membranes were washed with PBS containing Tween 20 0.5\%, reacted for $1 \mathrm{~h}$ at room temperature with horseradish peroxidase-labeled protein A, washed with PBS containing Tween $200.5 \%$, reacted with chemiluminescent reagents (Amersham) and then processed for autoradiography. Autoradiographic films were analyzed by densitometric scanning using the Kodak Image Station 440 System, supported by Kodak 1D Image Analysis Software. Results were expressed as arbitrary units $(\mathrm{AU}) / \mu \mathrm{g}$ total protein.

\section{Statistics}

Statistical analysis of data was performed with Statistica 6.0 (Statsoft Inc., Tulsa, OK, USA). When the effects of GC, IL-11 or IL-6 were studied, a multiple-measures ANOVA followed by the Newman-Keuls post-hoc comparison test was used. When the differences in GC effects in the cell lines were investigated, two-factor ANOVA was performed with one between-groups factor (cell type) and one within-subjects factor (cortisol concentration). $P<0 \cdot 05$ was considered to represent statistical significance.

\section{Results}

The functional phenotype assessed in our laboratory for these cell lines is presented in Table 1 . The capacity for releasing IL-6 and IL-11 was clearly different for Saos-2 vs MG-63 cells: the IL-6/IL-11 ratios in the medium were opposite, i.e. very low and very high respectively. Exposure of both cell lines to IL-1 $\beta$ resulted in a remarkable increase of cytokine release. Expression of GR was also very different in Saos-2 vs MG-63 cells, being approximately 3-fold higher in the latter. Neither cortisol nor IL-11 and IL-6 exerted any significant effect on cell count and viability in our experimental conditions. Cortisol at physiological and supraphysiological concentrations consistently inhibited both constitutive and inducible cytokine release (Fig. 2). Cortisol inhibition expressed as percent change vs control was more pronounced in MG-63 cells than in Saos-2 cells $(P<0 \cdot 02)$.

\section{Divergent effects of IL-11 and IL-6 on GR numbers}

MG-63 cells constitutively display a very high number of GRs; their production of IL-11 is poor in comparison to the abundance of that of IL-6. Exposure to increasing concentrations of IL-11 resulted in a parallel decrease of
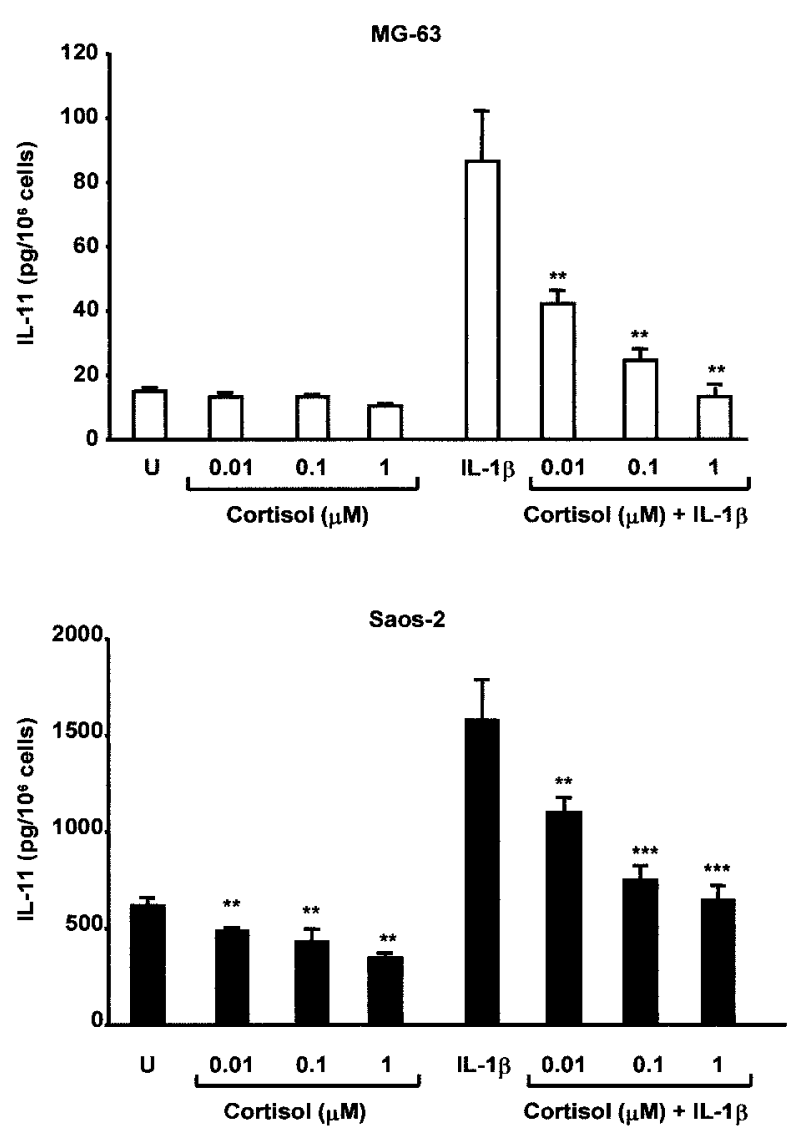

Figure 2 Inhibition of IL-11 release by cortisol in MG-63 and Saos-2 cells. Cells were incubated for $20 \mathrm{~h}$ with increasing concentrations of cortisol $(0 \cdot 01-1 \mu \mathrm{M})$, in the presence or absence of IL-1 $\beta(10 \mathrm{ng} / \mathrm{ml})$; after treatment, cell culture media were assayed for IL-11 by ELISA. Bars represent the means \pm S.E. of three independent experiments. ${ }^{* *} P<0 \cdot 01,{ }^{* * *} P<0 \cdot 001$ by multiple-measures ANOVA and Newman-Keuls post-hoc comparison test.

GR numbers. More than $40 \%$ reduction was attained with the maximal concentration of $100 \mathrm{ng} / \mathrm{ml}$ (Fig. 3). The effects of IL-11 were clearly divergent with respect to those of IL-6, which consistently led in the present and previous experiments to a dose-dependent increase of GR numbers.

Saos-2 cells constitutively display a relatively low number of GRs; their production of IL-11 is remarkably higher than that of IL-6. Again, clearly different effects of the exposure to IL-11 and IL-6 were noticed: while IL-6 was effective in enhancing GR numbers, no significant effect was apparent for IL-11.

In both cell lines, IL-11 deprivation by a monoclonal anti-hIL-11 antibody significantly increased GR numbers (Fig. 3). Neither exogenous IL-11 nor anti-hIL-11 antibody modified GR affinity expressed as $K_{\mathrm{d}}$ (data not shown). 

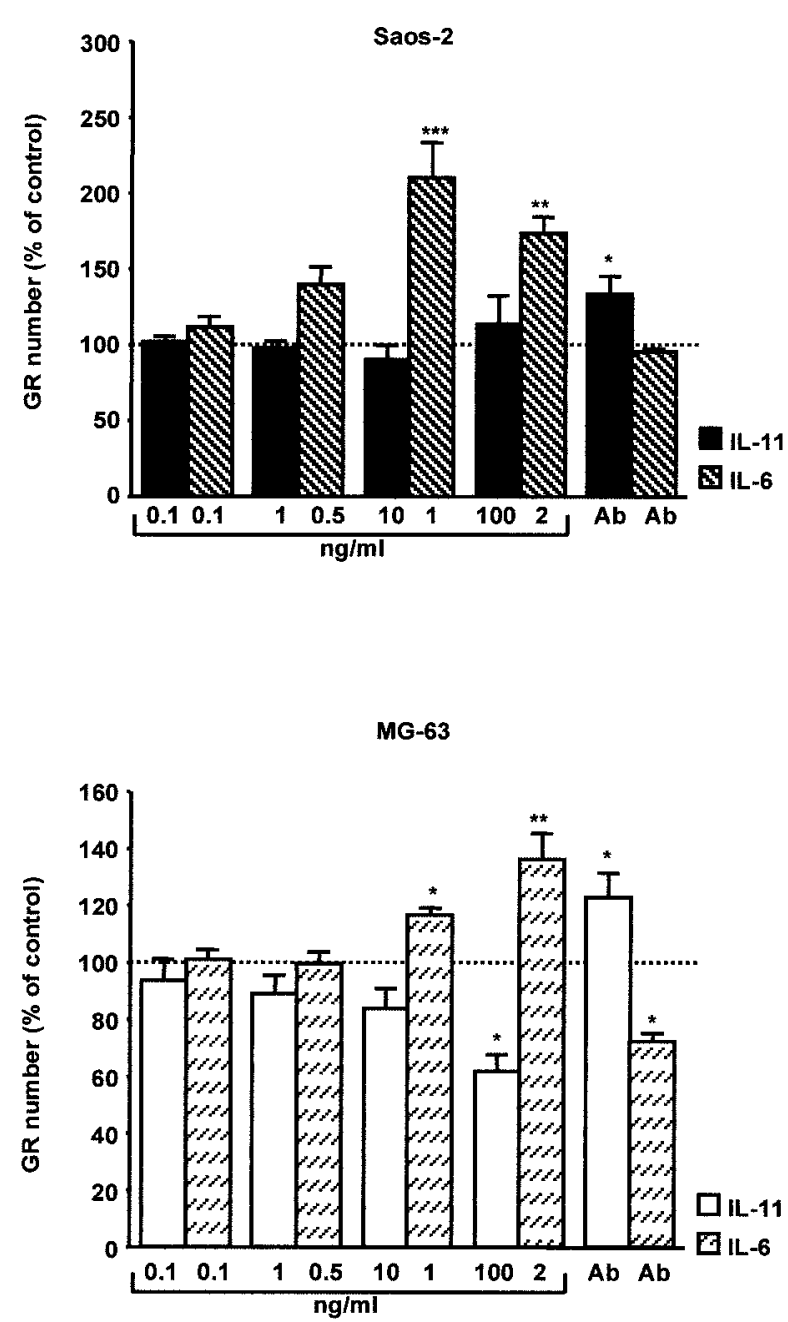

Figure 3 Effects of IL-11 and anti-hIL-11 antibody on GR number, compared with IL-6 and anti-hIL-6 antibody, in MG-63 and Saos-2 cells. Cells were incubated for $20 \mathrm{~h}$ with increasing concentrations of IL-11 $(0 \cdot 1-100 \mathrm{ng} / \mathrm{ml})$ or with anti-hIL-11 antibody (Saos-2: $1 \mu \mathrm{g} / \mathrm{ml}$; MG-63: $0.5 \mu \mathrm{g} / \mathrm{ml}$ ); in previous experiments, they were exposed to IL-6 $(0 \cdot 1-2 \mathrm{ng} / \mathrm{ml})$ or anti-IL-6 antibody (Saos-2: $10 \mathrm{ng} / \mathrm{ml}$; MG-63:100 ng/ml) for the same time. GR number and affinity were determined by radioligand binding assay. Bars represent the means \pm S.E. of at least four independent experiments. Ab, antibody. ${ }^{*} P<0 \cdot 05,{ }^{* *} P<0 \cdot 01,{ }^{* * *} P<0 \cdot 001$ by multiple-measures ANOVA and Newman-Keuls post-hoc comparison test.

The effects of IL-11 (10-100 ng/ml) on GR in MG-63 cells were confirmed by Western blot analysis using a specific anti-GR $\alpha$ antibody (Fig. 4).

Since reciprocal regulation of IL-6 and IL-11 has been reported (Trepicchio et al. 1996, Nakchbandi et al. 2001), we also measured IL-6 and IL-11 concentrations in the medium of cells exposed to IL-11, IL-6, anti-hIL-11 and anti-hIL-6 antibodies. No effect of IL-11 on IL-6 release, and vice versa, was observed $(n=3$, data not shown).
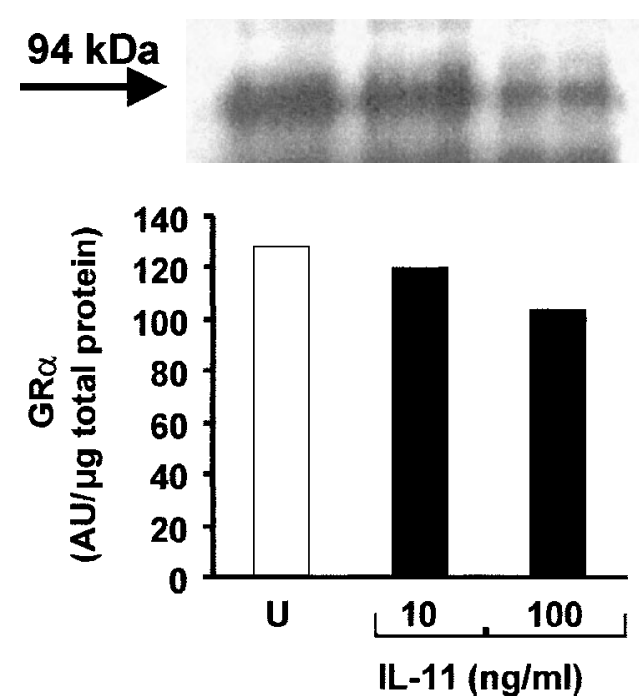

Figure 4 Effects of IL-11 (10 and $100 \mathrm{ng} / \mathrm{ml})$ on GR $\alpha$ protein expression in MG-63 cells. Top panel, representative Western blot analysis: $100 \mu \mathrm{g}$ of proteins were separated by SDS-PAGE and transferred to nitrocellulose membranes, which were then probed with a specific anti-GR $\alpha$ antibody. Bottom panel, signals corresponding to GR $\alpha$ were semi-quantified by densitometric scanning; data are expressed as AU/ $\mu$ g total protein.

\section{IL-11 and IL-6 do not modulate GC inhibitory effect on OPG release}

As expected, OPG levels in the medium of our cell lines were always measurable, yet at very different concentrations. In fact, MG-63 released about 50-fold more OPG than Saos-2 cells. On the other hand, free sRANKL was undetected in most samples. On these bases, we performed a series of experiments aimed to check effects of GCs and cytokines on OPG release. Cortisol and Dex significantly reduced OPG levels in the medium of both cell lines (Fig. 5). Cortisol inhibition expressed as percent change vs control was more pronounced in MG-63 cells than in Saos-2 cells $(P<0 \cdot 01)$. IL-11 and IL-6 slightly increased OPG release without attaining statistical significance (Fig. 6). Pre-exposure to IL-11 or IL-6 at concentrations able to respectively decrease or increase GR numbers did not significantly modify GC inhibition of OPG release (Fig. 7).

\section{Discussion}

IL-11 is a gp130-mediated cytokine which is expressed in bone microenvironment and acts on both osteoblasts and osteoclasts. Consistent with previous reports, we have shown that the two human osteoblast-like cell lines MG-63 and Saos-2 both release IL-11, although at different levels ( $\mathrm{Lu}$ et al. 1994), and that IL-1 $\beta$ stimulates release of IL-11 (Elias et al. 1995). Moreover, we have shown that 

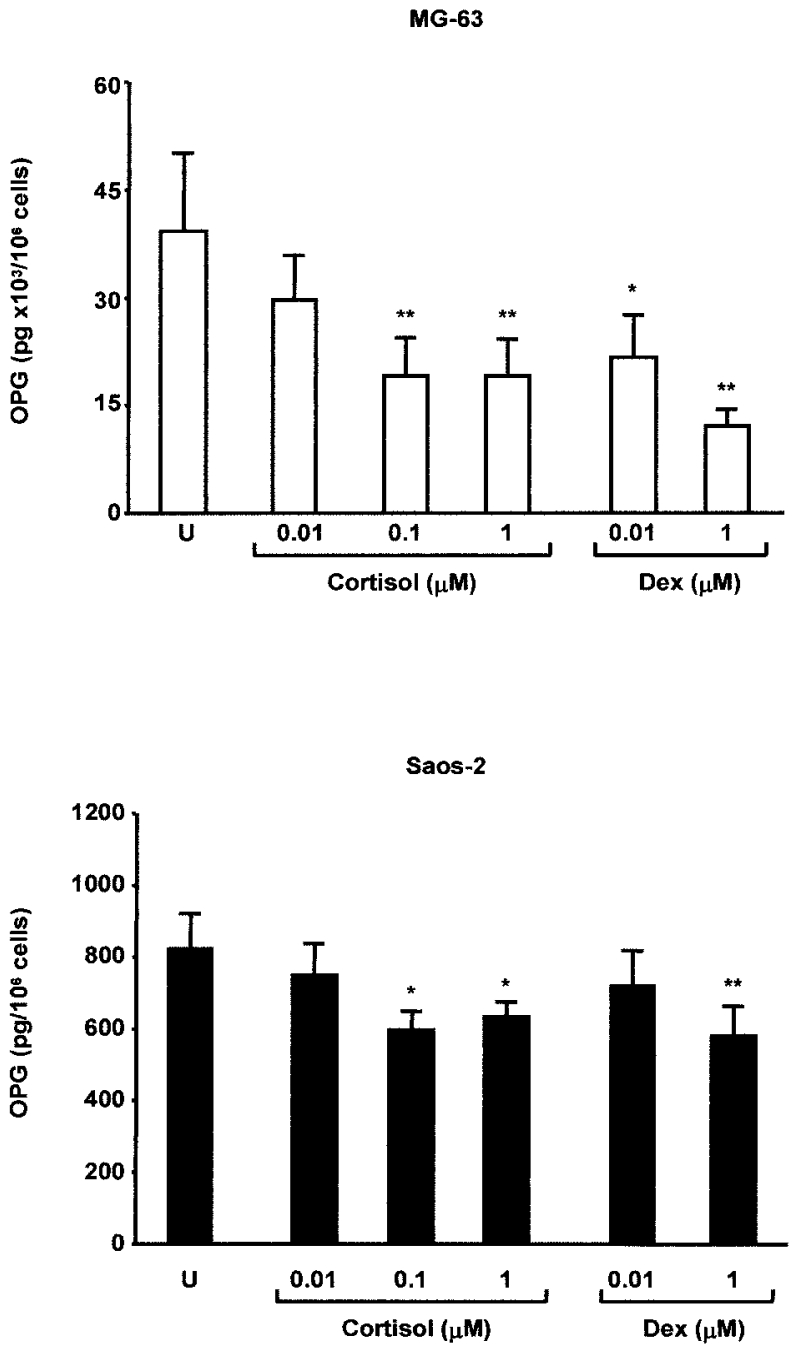

Figure 5 Inhibitory effects of GCs on OPG release in MG-63 and Saos- 2 cells. Cells were incubated for $20 \mathrm{~h}$ with increasing concentrations of cortisol or Dex $(0 \cdot 01-1 \mu \mathrm{M})$; after treatment, cell culture media were assayed for OPG by ELISA. Bars represent the means \pm S.E. of at least four independent experiments. ${ }^{*} P<0 \cdot 05$, ${ }^{*} P<0.01$ by multiple-measures ANOVA and Newman-Keuls post-hoc comparison test.

the human endogenous GC cortisol is able even at physiological concentrations to inhibit both the constitutive and IL-1 $\beta$-inducible IL-11 secretion. Our data complement previous observations that have dealt with the use of synthetic derivatives (Kim et al. 1999) and are compatible with the view that IL-11 is involved in the pathogenesis of osteoporosis due to both endogenous and exogenous GC excess (Kido et al. 2002).

The main finding of the present study, however, is the down-regulation of GR by IL-11. In the last decade, modulation of GR by cytokines has been demonstrated for IL-2, IL-4, tumor-necrosis factor- $\alpha$, IL-10, IL-1 $\alpha$ and

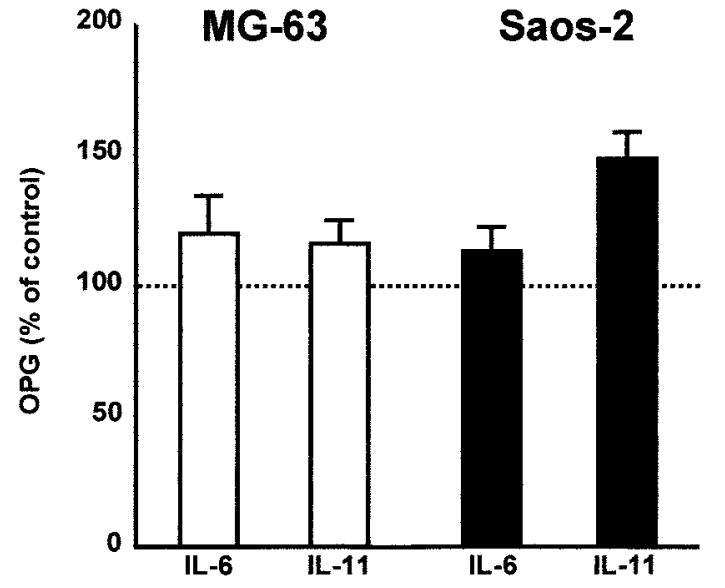

Figure 6 Stimulatory effects of IL- 6 and IL-11 on OPG release in MG-63 and Saos-2 cells. Cells were incubated for $20 \mathrm{~h}$ with IL-6 $(2 \mathrm{ng} / \mathrm{ml})$ or IL-11 $(100 \mathrm{ng} / \mathrm{ml})$; after treatment, cell culture media were assayed for OPG by ELISA. Data are expressed as percent of control; each bar represents the mean \pm S.E. of at least five independent experiments.

$-\beta$ in different GC-responsive cells (Kam et al. 1993, Verheggen et al. 1996, Sartori et al. 1998, Franchimont et al. 1999, Webster et al. 2001). With regard to IL-6, this cytokine has been shown to up-regulate GR in cells of Kaposi's sarcoma (Guo et al. 1996), lymphoid (Rakasz et al. 1993) and osteoblast-like cells (Dovio et al. 2001b). To the best of our knowledge, the present report is the first dealing with a modulatory effect of IL-11 on GR. In our experimental conditions, IL-11 significantly decreased GR numbers in MG-63 but not in Saos-2 cells. This could be attributable to the different constitutive expression of IL-11, which is much higher in Saos-2 than in MG-63 cells. Data obtained with the use of a highly specific anti-hIL-11 antibody are consistent with an autocrine down-modulatory effect. It is reasonable to think that in Saos- 2 cells the constitutive production is enough to attain the effect at the best of its potentiality; consequently, only the deprivation (and not the addition) of the cytokine could result effectively in changing GR numbers. On the other hand, in MG-63 cells the constitutive production of IL-11 is much lower. This offers an explanation for the fact that exogenous enrichment of the signal significantly decreases the same binding. Taken together, our previous and present findings point to an opposite regulatory role of IL-6 and IL-11 upon GR numbers in osteoblast-like cells, positive and negative respectively.

It could seem surprising that IL-6 and IL-11, which belong to the same cytokine family and transduce through the same signaling molecule, are able to exert divergent effects in the same cell type. Indeed, IL-6 and IL-11 have different roles in vivo, as suggested by knock-out models (Poli et al. 1994, Sims et al. 2002). It is not clear whether such differences result from different expression 

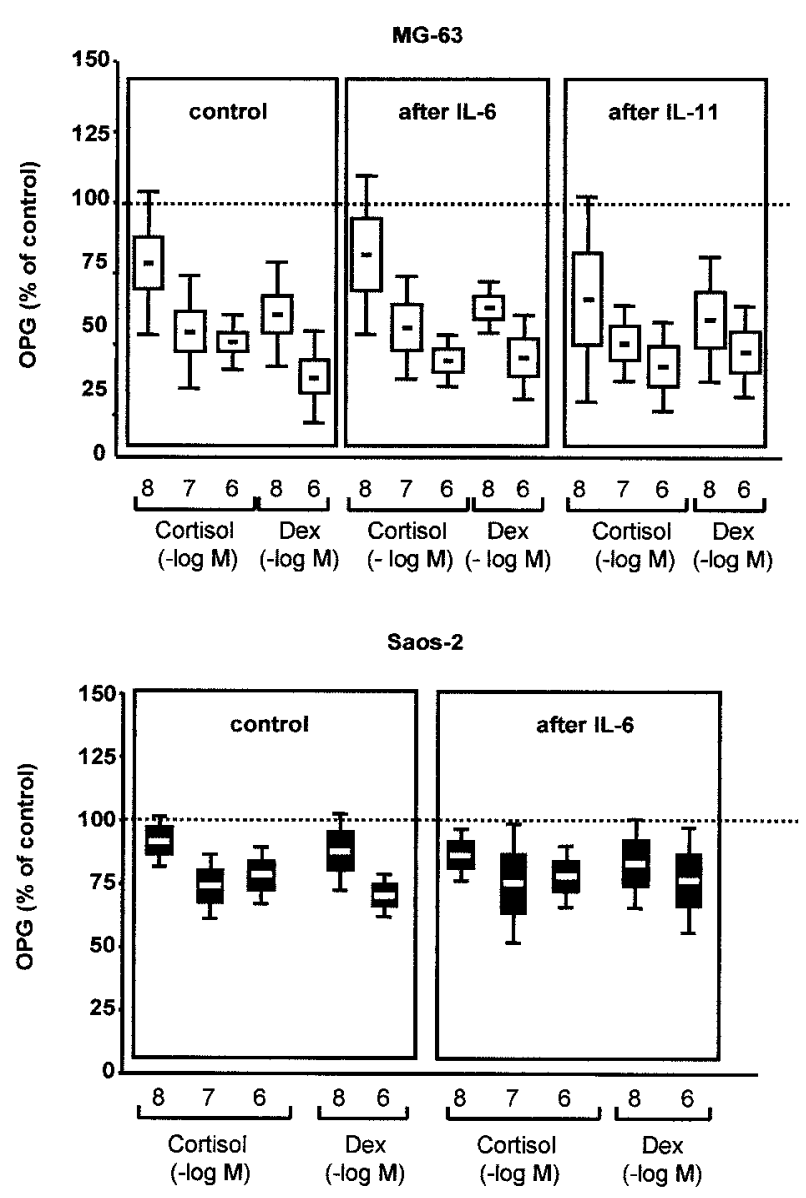

Figure 7 Effects of IL- 6 and IL-11 on GC-induced inhibition of OPG release by MG-63 and Saos- 2 cells. Cells were incubated with vehicle, IL-6 (2 ng/ml) or IL-11 (100 ng/ml) for $20 \mathrm{~h}$; then cell culture media were removed and the same cells were further incubated for $20 \mathrm{~h}$ with either vehicle or cortisol and Dex (0.01-1 $\mu \mathrm{M})$; after treatment, cell culture media were harvested and assayed for OPG by ELISA. Data are expressed as percent of control; boxes represent means \pm S.E., whiskers represent means \pm S.D. of at least five independent experiments.

and regulation of specific receptor subunits in the target cells, or from different patterns of activation of intracellular pathways also. In this respect, it has been reported that ternary complexes of IL-11-IL-11 receptor-gp130 and IL-6-IL-6 receptor-gp130 have a very similar overall geometry and activate the same Jak-STAT pathway, but different biological responses in the same cell type could depend on additional receptor components or differences in the kinetics of ligand-receptor complex formation (Dahmen et al. 1998). As a matter of fact, in murine peritoneal macrophages, IL-11 and IL-6 transduction pathways have been demonstrated to be different, in that both IL-6 and IL-11 activated STAT3, whereas IL-6 but not IL-11 activated STAT1 (Trepicchio \& Dorner 1998). Differences in other gp130-activated pathways, such as the
SHP-2/MAP kinases pathway, could also be relevant to this point.

Since IL-11 has been shown to down-regulate lipopolysaccharide-induced IL-6 release by macrophages (Trepicchio et al. 1996), and IL-6 has been found to down-regulate parathyroid hormone-induced IL-11 release by osteoblasts (Nakchbandi et al. 2001), reciprocal regulation could be involved in the observed divergent effects on GR. An additional support to this interpretation could come from the inverse constitutive expression of these cytokines in our cell lines. Nonetheless, it seems not to be the case, since neither exposure to IL-11 or anti-hIL-11 antibody modified IL-6 release, nor exposure to IL-6 or anti-hIL-6 antibody modulated IL-11 release in both cell lines. Our data do not exclude the possibility that reciprocal inhibitory effects may occur when cytokines release is induced by appropriate secretagogues; however, at least under basal conditions, the mechanisms by which IL-11 down-regulates GR are likely to be independent of IL-6, and need further investigation. Since IL-11 has been found to up-regulate IKB $\alpha$ (Trepicchio et al. 1997), the recent description of an NF- $\kappa \mathrm{B}$ response element in the promoter region of GR gene could be of relevance (Webster et al. 2001).

Consistent with previous reports, we have shown that both Saos-2 and MG-63 cells express OPG, although at quite different levels (Vidal et al. 1998a, Kinpara et al. 2000). On the other hand, we could not detect appreciable levels of free sRANKL in our media. This could be due to intrinsic limitations of currently available ELISAs, which utilize OPG as an immobilized capture component and therefore may be interfered with by OPG content in the sample (Kinpara et al. 2000). RANKL/OPG ratio is admittedly a major determinant of osteoclastogenesis, osteoclast activity and apoptosis, and therefore of bone resorption (Hofbauer \& Heufelder 2000, Horowitz et al. 2001). We have confirmed a strong inhibitory effect of both cortisol (at physiological and supraphysiological concentrations) and Dex on OPG release. GC-induced inhibition of OPG expression is likely to be due to genomic mechanisms, since it has been reported to take some hours (Vidal et al. 1998a); moreover, our data suggest that such an inhibition is GR- rather than mineralocorticoid receptor-mediated, since similar effects were elicited by cortisol and Dex as well.

Treatment with IL-6 and IL-11 slightly increased OPG release in our cells. Data on the effects on OPG expression of gp130 cytokines are still conflicting (Horwood et al. 1998, Vidal et al. 1998b, Aubin \& Bonnelye 2000, Yano et al. 2001, Ragab et al. 2002). It is widely accepted, however, that cells of the osteoblastic lineage exposed to these cytokines up-regulate osteoclastogenesis. Pertinently, it has been demonstrated that IL-11 up-regulates both RANKL and OPG mRNAs; yet the net balance is an increased RANKL/OPG ratio, hence a pro-resorptive signal (Horwood et al. 1998). 
Limitations of our study should be noted. First, it deals with osteosarcoma cell lines, and not with primary cultures of normal osteoblasts. Secondly, we failed to demonstrate any change in GC sensitivity. In fact, we have found that while modulating GR number, neither IL-6 nor IL-11 significantly modified the inhibitory effects of GCs on OPG release. An explanation could be seen in the redundancy of GR for the genomic regulation of OPG expression: Saos-2 and MG-63 cells show 4-5- and 20-25-fold respectively higher concentrations of GR than other GC-responsive cells, such as peripheral blood mononuclear cells (Sartori et al. 1998). It is worthy noticing, however, that the GC-dependent inhibition of OPG release was more apparent in MG-63 than in Saos-2 cells, consistent with the differences in GR numbers. Also the inhibitory effect of cortisol on IL-1 $\beta$-induced cytokine release was more pronounced in the cell line expressing more binding. Alternatively, the cytokine effects on GR numbers could be minimized by compensatory changes in other molecular determinants of GC sensitivity.

In conclusion, this is the first study to show a modulatory effect of IL-11 on GR. In this respect, it complements our previous work on IL-6. Divergent effects of IL-11 and IL-6 on two osteoblast-like cell lines are consistent with partly different intracellular pathways of signal transduction. Surprisingly, in our experimental conditions neither IL-6 nor IL-11 significantly modified GC sensitivity of the OPG gene, assessed by OPG release into the culture medium. Nonetheless, since it has been demonstrated that GR number is a key determinant of GC sensitivity, it is conceivable that modulation of GR by IL-6 and IL-11 is of relevance for other GC-responsive genes. Taken together, our data support the concept of autocrine-paracrine modulation by pro- and anti-inflammatory cytokines upon the molecular determinants of GC sensitivity in bone microenvironment.

\section{Acknowledgements}

This work was supported by grants from MURST ex-60\% and Progetto Giovani Ricercatori (Rome, Italy), Cassa di Risparmio di Cuneo (Cuneo, CN, Italy), Cassa di Risparmio di Saluzzo (Saluzzo, CN, Italy) and Novartis Farma SpA (Origgio, VA, Italy). The authors are also grateful to Dr Laura Saba for her technical assistance.

\section{References}

Aubin JE \& Bonnelye E 2000 Osteoprotegerin and its ligand: a new paradigm for regulation of osteoclastogenesis and bone resorption. Osteoporosis International 11 905-913.

Canalis E \& Giustina A 2001 Glucocorticoid-induced osteoporosis: summary of a workshop. Journal of Clinical Endocrinology and Metabolism 86 5681-5685.

Dahmen H, Horsten U, Kuster A, Jacques Y, Minvielle S, Kerr IM, Ciliberto G, Paonessa G, Heinrich PC \& Muller-Newen G 1998
Activation of the signal transducer gp130 by interleukin-11 and interleukin-6 is mediated by similar molecular interactions. Biochemical Journal 331 695-702.

Dovio A, Sartori ML, Masera RG, Racca S \& Angeli A 2001a Inhibitory effect of physiological concentrations of cortisol but not estradiol on interleukin (IL)-6 production by human osteoblast-like cell lines with different constitutive IL-6 expression. Cytokine 15 $47-52$.

Dovio A, Masera RG, Sartori ML, Racca S \& Angeli A $2001 b$ Autocrine up-regulation of glucocorticoid receptors by interleukin-6 in human osteoblast-like cells. Calcified Tissue International 69 293-298.

Elias JA, Tang W \& Horowitz MC 1995 Cytokine and hormonal stimulation of human osteosarcoma interleukin-11 production. Endocrinology 136 489-498.

Franchimont D, Martens H, Hagelstein MT, Louis E, Dewe W, Chrousos GP, Belaiche J \& Geenen V 1999 Tumor necrosis $\alpha$ decreases, and interleukin-10 increases, the sensitivity of human monocytes to dexamethasone: potential regulation of the glucocorticoid receptor. Journal of Clinical Endocrinology and Metabolism 84 2834-2839.

Girasole G, Passeri G, Jilka RL \& Manolagas SC 1994 Interleukin-11: a new cytokine critical for osteoclast development. Journal of Clinical Investigation 93 1516-1524.

Guo WX, Antakly T, Cadotte M, Kachra Z, Kunkel L, Masood R \& Gill P 1996 Expression and cytokine regulation of glucocorticoid receptors in Kaposi's sarcoma. American Journal of Pathology 148 1999-2008.

Heinrich PC, Behrmann I, Müller-Newen G, Schaper F \& Graeve L 1998 Interleukin-6-type cytokine signalling through the gp130/Jak/STAT pathway. Biochemical Journal 334 297-314.

Hofbauer LC \& Heufelder AE 2000 Clinical review 114: hot topic. The role of receptor activator of nuclear factor-kappaB ligand and osteoprotegerin in the pathogenesis and treatment of metabolic bone diseases. Journal of Clinical Endocrinology and Metabolism 85 2355-2363.

Horowitz MC, Xi Y, Wilson K \& Kacena MA 2001 Control of osteoclastogenesis and bone resorption by members of the TNF family of receptors and ligands. Cytokine and Growth Factor Reviews 12 9-18.

Horwood NJ, Elliott J, Martin TJ \& Gillespie MT 1998 Osteotropic agents regulate the expression of osteoclast differentiation factor and osteoprotegerin in osteoblastic stromal cells. Endocrinology 139 4743-4746.

Kam JC, Szefler SJ, Surs W, Sher ER \& Leung DY 1993 Combination IL-2 and IL-4 reduces glucocorticoid receptor-binding affinity and $\mathrm{T}$ cell response to glucocorticoids. Journal of Immunology $1513460-3466$.

Kido S, Inoue D, Kato S, Ito Y \& Matsumoto T 2002 Downregulation of interleukin-11 may be involved in the pathogenesis of glucocorticoid-induced osteoporosis. Journal of Bone and Mineral Research 17 (Suppl 1) S134.

Kim CH, Cheng SL \& Kim GS 1999 Effects of dexamethasone on proliferation, activity, and cytokine secretion of normal human bone marrow stromal cells: possible mechanisms of glucocorticoidinduced bone loss. Journal of Endocrinology 162 371-379.

Kinpara K, Mogi M, Kuzushima M \& Togari A 2000 Osteoclast differentiation factor in human osteosarcoma cell line. Journal of Immunoassay 21 327-340.

Kodama Y, Takeuchi Y, Suzawa M, Fukumoto S, Murayama H, Yamato H, Fujita T, Kurokawa T \& Matsumoto T 1998 Reduced expression of interleukin-11 in bone marrow stromal cells of senescence-accelerated mice (SAMP6): relationship to osteopenia with enhanced adipogenesis. Journal of Bone and Mineral Research 13 1370-1377.

Laudet V \& Gronemeyer H 2002 GR. In The Nuclear Receptor Factsbook, pp 345-367. Eds V Laudet \& H Gronemeyer. London, San Diego: Academic Press. 
Lu ZY, Zhang XG, Gu ZJ, Yasukawa K, Amiot M, Etrillard M, Bataille R \& Klein B 1994 A highly sensitive quantitative bioassay for human interleukin-11. Journal of Immunological Methods $\mathbf{1 7 3}$ $19-26$.

Nakchbandi IA, Mitnick MA, Masiukiewicz US, Sun BH \& Insogna KL 2001 IL-6 negatively regulates IL-11 production in vitro and in vivo. Endocrinology 142 3850-3856.

Nicholas J, Ruvolo VR, Burns WH, Sandford G, Wan X, Ciufo D, Hendrickson SB, Guo HG, Hayward GS \& Reitz MS 1997 Kaposi's sarcoma-associated human herpesvirus- 8 encodes homologues of macrophage inflammatory protein-1 and interleukin-6. Nature Medicine 3 287-292.

Poli V, Balena R, Fattori E, Markatos A, Yamamoto M, Tanaka H, Ciliberto G, Rodan GA \& Costantini F 1994 Interleukin-6 deficient mice are protected from bone loss caused by estrogen depletion. EMBO Journal 13 1189-1196.

Ragab AA, Nalepka JL, Bi Y \& Greenfield EM 2002 Cytokines synergistically induce osteoclast differentiation: support by immortalized or normal calvarial cells. American Journal of Physiology. Cell Physiology 283 C679-C687.

Rakasz E, Gal A, Biro J, Balas G \& Falus A 1993 Modulation of glucocorticosteroid binding in human lymphoid, monocytoid and hepatoma cell lines by inflammatory cytokines interleukin (IL)-1 beta, IL-6 and tumour necrosis factor (TNF)-alpha. Scandinavian Journal of Immunology 37 684-689.

Reichardt HM, Umland T, Bauer A, Kretz O \& Schutz G 2000 Mice with an increased glucocorticoid receptor gene dosage show enhanced resistance to stress and endotoxic shock. Molecular and Cellular Biology 20 9009-9017.

Sartori ML, Masera RG, Staurenghi A, Racca S \& Angeli A 1998 Interleukin 2 up-regulates glucocorticoid receptor number in human peripheral blood mononuclear cells and the osteosarcoma cell line Saos-2 in vitro. Steroids 63 349-351.

Senaldi G, Varnum BC, Sarmiento U, Starnes C, Lile J, Scully S, Guo J, Elliott G, McNinch J, Shaklee CL et al. 1999 Novel neurotrophin-1/B cell-stimulating factor-3: a cytokine of the IL-6 family. PNAS 96 11458-11463.

Sims NA, Jenkins BJ, Quinn JMW, Ng KW, Martin TJ, Gillespie MT, Robb L \& Ernst M 2002 Interleukin-11 receptor signaling is required for normal bone remodeling in male and female mice. Journal of Bone and Mineral Research 17 (Suppl 1) S143.

Suga K, Saitoh M, Fukushima S, Takahashi K, Nara H, Yasuda S \& Miyata K 2001 Interleukin-11 induces osteoblast differentiation and acts synergistically with bone morphogenetic protein- 2 in C3H10T1/2 cells. Journal of Interferon and Cytokine Research $\mathbf{2 1}$ 695-707.

Taguchi Y, Yamamoto M, Yamate T, Lin SC, Mocharla H, DeTogni P, Nakayama N, Boyce BF, Abe E \& Manolagas SC
1998 Interleukin-6-type cytokines stimulate mesenchymal progenitor differentiation toward the osteoblastic lineage. Proceedings of the Association of American Physicians 110 559-574.

Takeuchi Y, Watanabe S, Ishii G, Takeda S, Nakayama K, Fukumoto S, Kaneta Y, Inoue D, Matsumoto T, Harigaya K et al. 2002 Interleukin-11 as a stimulatory factor for bone formation prevents bone loss with advancing age in mice. Journal of Biological Chemistry 277 49011-49018.

Trepicchio WL \& Dorner AJ 1998 Interleukin-11. A gp130 cytokine. Annals of the New York Academy of Sciences 856 12-21.

Trepicchio WL, Bozza M, Pedneault G \& Dorner AJ 1996 Recombinant human IL-11 attenuates the inflammatory response through down-regulation of proinflammatory cytokine release and nitric oxide production. Journal of Immunology 157 3627-3634.

Trepicchio WL, Wang L, Bozza M \& Dorner AJ 1997 IL-11 regulates macrophage effector function through the inhibition of nuclear factor-kappaB. Journal of Immunology 159 5661-5670.

Verheggen MM, van Hal PT, Adriaansen-Soeting PW, Goense BJ, Hoogsteden HC, Brinkmann AO \& Versnel MA 1996 Modulation of glucocorticoid receptor expression in human bronchial epithelial cell lines by IL-1 beta, TNF-alpha and LPS. European Respiratory Journal 9 2036-2043.

Vidal ON, Brandstrom H, Jonsson KB \& Ohlsson C 1998a Osteoprotegerin mRNA is expressed in primary human osteoblast-like cells: down-regulation by glucocorticoids. Journal of Endocrinology 159 191-195.

Vidal ON, Sjogren K, Eriksson BI, Ljunggren O \& Ohlsson C 19986 Osteoprotegerin mRNA is increased by interleukin-1 alpha in the human osteosarcoma cell line MG-63 and in human osteoblast-like cells. Biochemical and Biophysical Research Communications 248 696-700.

Webster JC, Oakley RH, Jewell CM \& Cidlowski JA 2001 Proinflammatory cytokines regulate human glucocorticoid receptor gene expression and lead to the accumulation of the dominant negative beta isoform: a mechanism for the generation of glucocorticoid resistance. PNAS 98 6865-6870.

Weinstein R 2001 Glucocorticoid-induced osteoporosis. Reviews in Endocrine and Metabolic Disorders 2 65-73.

Yano K, Nakagawa N, Yasuda H, Tsuda E \& Higashio K 2001 Synovial cells from a patient with rheumatoid arthritis produce osteoclastogenesis inhibitory factor/osteoprotegerin: reciprocal regulation of the production by inflammatory cytokines and basic fibroblast growth factor. Journal of Bone and Mineral Metabolism 19 $365-372$

Received 5 December 2002

Accepted 8 January 2003 